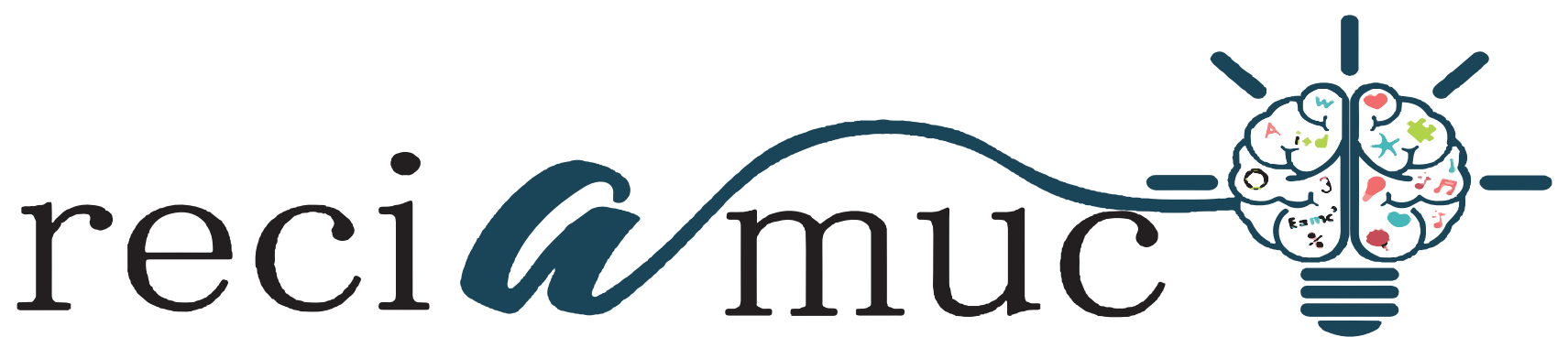

DOI: 10.26820/reciamuc/5.(4).noviembre.2021.181-195

URL: https://reciamuc.com/index.php/RECIAMUC/article/view/740

EDITORIAL: Saberes del Conocimiento

REVISTA: RECIAMUC

ISSN: 2588-0748

TIPO DE INVESTIGACióN: Artículo de Revisión

Código UNESCO: 32 Ciencias Médicas

PAGINAS: $181-195$

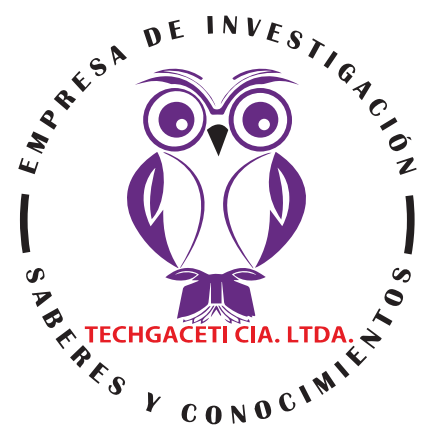

\title{
Diagnóstico y clasificación de COVID-19 basado en imágenes
}

Image-based diagnosis and classification of COVID-19 Diagnóstico baseado em imagem e classificação de COVID-19

Jessica Ariana Guerra Fernández'; Carlos Andrés Villao Navas²; Sofia Alejandra Santos Benavides³

\section{RECIBIDO: 15/09/2021 ACEPTADO: 05/10/2021 PUBLICADO: 29/11/2021}

1. Magister en Seguridad y Salud Ocupacional; Médica; Investigador Independiente; Guayaquil, Ecuador; jeguerra.md@gmail.com; iD https://orcid.org/0000-0002-1066-6610

2. Médico; Investigador Independiente; Guayaquil, Ecuador; andnav007@gmail.com; (iD https://orcid.org/00000002-2940-1225

3. Médico; Investigador Independiente; Guayaquil, Ecuador; sofilusantos@hotmail.com; iD https://orcid.org/00000002-8497-0447

\section{CORRESPONDENCIA \\ Jessica Ariana Guerra Fernández \\ jeguerra.md@gmail.com \\ Guayaquil, Ecuador}

() RECIAMUC; Editorial Saberes del Conocimiento, 2021 


\section{RESUMEN}

La COVID-19 es una enfermedad infecciosa internacional provocada por una cepa de coronavirus nunca antes identificada. La pandemia por el SARS-CoV-2 está cambiando paradigmas en el control y el manejo de las enfermedades infecciosas. Esta investigación se limita a la búsqueda y revisión de material bibliográfico que mediante el uso de diversas bases de datos como MedlinePlus, PubMed, Biblioteca Virtual de la Salud (BVS), SciELO, Dialnet y ELSEVIER se sintetizó la mejor evidencia disponible usando las expresiones "diagnóstico de COVID-19", "Clasificación de COVID-19"; "COVID-19 diagnostico por imagen" y "Clasificación de COVID-19 por imágenes. El rol de las imágenes diagnósticas se hace cada día más relevante en medio de la pandemia, pues queda demostrada su importancia como diagnóstico, protocolo de tratamiento y seguimiento en el paciente positivo con COVID-19. Las distintas variantes que se han conocido del SARS-COV-2 mantiene en alerta a todo profesional médico y técnico en el área de la salud y la medicina, pues se siguen descubriendo características distintas de manifestaciones clínicas en pacientes con COVID-19, lo que permite inferir que lo que ya se conoce es apenas un inicio, y que se deben seguir desarrollando tecnologías que agrupen los conocimientos desarrollados y propicien los nuevos. E apoyo en la biotecnología es una oportunidad para enfrentar esta pandemia, definitivamente la capacidad de la Inteligencia Artificial (IA) en el almacenaje de información, la relación de patrones y la velocidad de diagnóstico es una oportunidad única que ofrece la evolución científica frente a los eventos pandémicos vivimos por la humanidad. Es crucial el papel que desempeñan los elementos humanos en la parametrización, prueba y aprobación de tecnologías útiles que mejore el alcance la atención médica para ganar la batalla en contra del SARS-COV-2 y la COVID-19.

Palabras clave: Enfermedades infecciosas, pandemia, coronavirus, estudio de imágenes, SARS-COV-2, COVID-19.

\section{ABSTRACT}

COVID-19 is an international infectious disease caused by a never-before-identified strain of coronavirus. The SARS-CoV-2 pandemic is changing paradigms in the control and management of infectious diseases. This research is limited to the search and review of bibliographic material that through the use of various databases such as MedlinePlus, PubMed, Virtual Health Library (VHL), SciELO, Dialnet and ELSEVIER, the best available evidence was synthesized using the expressions " diagnosis of COVID-19 ", Classification of COVID-19 "; "COVID-19 diagnosis by image" and "Classification of COVID-19 by images. . The role of diagnostic images is becoming more relevant every day in the midst of the pandemic, as its importance as a diagnosis, treatment protocol and follow-up in the positive patient with COVID-19 is demonstrated. The different variants that have been known of SARS-COV-2 keep all medical and technical professionals in the area of health and medicine on alert, since different characteristics of clinical manifestations continue to be discovered in patients with COVID-19, which it allows us to infer that what is already known is just a beginning, and that technologies must continue to be developed that bring together the knowledge developed and promote new ones. Support in biotechnology is an opportunity to face this pandemic, definitely the capacity of Artificial Intelligence (AI) in the storage of information, the relationship of patterns and the speed of diagnosis is a unique opportunity offered by scientific evolution against the pandemic events we live for humanity. The role that human elements play in parameterizing, testing, and approving useful technologies that improve healthcare outreach are crucial to winning the battle against SARS-COV-2 and COVID-19.

Keywords: Infectious diseases, pandemic, coronavirus, imaging study, SARS-COV-2, COVID-19.

\section{RESUMO}

COVID-19 é uma doença infecciosa internacional causada por uma cepa de coronavírus nunca identificada antes. A pandemia SARS-CoV-2 está mudando paradigmas no controle e gerenciamento de doenças infecciosas. Esta pesquisa se limita à busca e revisão de material bibliográfico que, por meio da utilização de diversas bases de dados como MedlinePlus, PubMed, Biblioteca Virtual em Saúde (BVS), SciELO, Dialnet e ELSEVIER, as melhores evidências disponíveis foram sintetizadas a partir das expressões "diagnóstico de COVID-19 "," Classificação do COVID-19 ";" Diagnóstico do COVID-19 por imagem "e" Classificação do COVID-19 por imagens. . O papel das imagens diagnósticas torna-se cada vez mais relevante em meio à pandemia, à medida que se demonstra sua importância como diagnóstico, protocolo de tratamento e acompanhamento do paciente positivo com COVID-19. As diferentes variantes conhecidas do SARS-COV-2 mantêm todos os profissionais médicos e técnicos da área da saúde e da medicina em alerta, visto que continuam a ser descobertas diferentes características das manifestações clínicas nos doentes com COVID-19, o que nos permite inferir que o que já se sabe é apenas um começo, e que devem continuar a ser desenvolvidas tecnologias que reúnam os conhecimentos desenvolvidos e promovam novos. O apoio em biotecnologia é uma oportunidade de enfrentar esta pandemia, definitivamente a capacidade da Inteligência Artificial (IA) no armazenamento de informações, a relação de padrões e a velocidade de diagnóstico é uma oportunidade única oferecida pela evolução científica contra os eventos pandêmicos que vivemos humanidade. O papel que os elementos humanos desempenham na parametrização, teste e aprovação de tecnologias úteis que melhoram o alcance da saúde são cruciais para vencer a batalha contra o SARS-COV-2 e o COVID-19.

Palavras-chave: Doenças infecciosas, pandemia, coronavírus, estudo de imagem, SARS-COV-2, COVID-19. 


\section{Introducción}

La COVID-19 es una enfermedad infecciosa internacional provocada por una cepa de coronavirus nunca antes identificada, la cual amenaza a la población desde finales del año 2019.y por su facilidad para expandirse, la Organización Mundial de la Salud (OMS) declaró una emergencia sanitaria a nivel mundial el 11 de marzo de 2020. (Pérez Ortiz, 2021)

La pandemia por el SARS-CoV-2 está cambiando paradigmas en el control y el manejo de las enfermedades infecciosas. Una proporción mayor al 30\% de infectados son asintomáticos, pero actúan como diseminadores; el otro $70 \%$, según la clasificación clínica de Wuhan, desarrolla formas leves, moderadas, severas o críticas. La edad avanzada, la diabetes, la obesidad, la hipertensión arterial, otras enfermedades cardiovasculares y pulmonares crónicas son factores asociados a formas severas o letales. (Mendoza-Ticona, y otros, 2020)

Según Dong, et al (2020) una de las variantes usadas empleadas en la detección temprana y manejo oportuno de pacientes positivos a COVID-19 se basa en el análisis de imágenes médicas. Específicamente los especialistas se basan en estudios radiológicos, ya sea por radiografía de tórax (CXR) o tomografía computarizada (CT) para seguir la evolución de la enfermedad (López Cabrera, Portal Díaz, Orozco Morales, \& Pérez Díaz, 2020)

Tabla 1. Usos principales de imágenes avanzadas durante la pandemia COVID-19.

\begin{tabular}{|c|c|c|}
\hline & Tomografía Computada & Resonancia Magnética \\
\hline $2-$ & $\begin{array}{l}\text { Exclusión de trombosis del } \\
\text { apéndice auricular izquierdo o } \\
\text { posible trombosis intracavitaria. } \\
\text { Exclusión de enfermedad coronaria } \\
\text { obstructiva en pacientes con dolor } \\
\text { de pecho agudo y troponinas } \\
\text { negativas o mínimamente elevadas } \\
\text { cuando el diagnóstico es incierto. } \\
\text { Exclusión de absceso y otras } \\
\text { complicaciones de la endocarditis } \\
\text { infecciosa de válvula nativa o } \\
\text { protésica. } \\
\text { Disfunción valvular protésica aguda } \\
\text { sintomática. }\end{array}$ & $\begin{array}{l}\text { 1- Evaluación de la miocarditis aguda } \\
\text { en casos donde el estudio } \\
\text { modifique el manejo clínico. } \\
\text { 2- Diagnóstico de infarto agudo del } \\
\text { miocardio sin enfermedad } \\
\text { coronaria obstructiva. }\end{array}$ \\
\hline
\end{tabular}

Fuente: (Slipczuk, y otros, 2021) 
Nos hemos propuesto hacer una revisión bibliográfica respecto al diagnóstico y clasificación de la COVID-19 a través de las imágenes.

\section{Metodología}

Para el desarrollo de la presente investigación se usaron computadores personales con conexión a internet, con el propósito de exponer acerca del diagnóstico y clasificación de COVID-19 basado en imágenes, en virtud de lo cual, el mismo se enmarca en un diseño de investigación documental o bibliográfica. Esta investigación se limita a la búsqueda y revisión de material bibliográfico que, por una parte, es accesible mediante el uso de diversas bases de datos, entre las que figuraron: MedlinePlus, PubMed, Biblioteca Virtual de la Salud (BVS), SciELO, Dialnet y ELSEVIER, entre otras; mediante las cuales se sintetizó la mejor evidencia disponible.

Se realizó una búsqueda aleatoria y consecutiva, usando las expresiones "diagnostico de COVID-19", "Clasificación de COVID-19"; "COVID-19 diagnostico por imagen" y "Clasificación de COVID-19 por imágenes", lo que aproximadamente resultó en más de un centenar de miles de registros bibliográficos que luego se fueron filtrando bajo los criterios de idioma español, relevancia, correlación temática y fecha de publicación en los últimos, sin descartar por tipo de material bibliográfico.

Por último, se le da la correspondiente lectura crítica y análisis de toda esa evidencia científica, lo que resultó en el contenido del presente trabajo.

\section{Resultados}

Para definir los estadios clínicos de la COVID-19 necesitamos médicos capacitados en la primera línea de atención. Con una correcta evaluación clínica epidemiológica, una placa de tórax (idealmente tomografía), hemograma, proteína $\mathrm{C}$ reactiva cuantitativa, dímero-D, ferritina, deshidrogenasa láctica y gases arteriales, se debe definir el estadio y el manejo de los pacientes. El tiempo de enfermedad es crucial ya que se ha visto que la tormenta de citoquinas suele presentarse alrededor del séptimo día desde el inicio de síntomas. (Mendoza-Ticona, y otros, 2020)

Los principales hallazgos pulmonares del COVID-19 complementarios en sospecha diagnóstica clínica alta pero RT-PCR negativa serían:

Radiografía: Se presenta clásicamente como infiltrados bilaterales subpleurales en $75 \%$ de los casos, sin embargo, una cuarta parte tendrán compromiso unilateral únicamente. (Madrigal-Rojas, Quesara-Loria, García-Sanchez, \& Solano-Chinchilla, 2020)

La radiografía de tórax es económica y accesible, es un método de fácil consecución que posibilita la orientación del paciente al ingreso, en especial aquellos sospechosos de poseer el virus y con características clínicas compatibles con infección moderada o severa. Este abordaje inicial ayuda a detectar particularidades relacionadas con neumonía, asimismo, consiente proporcionar un diagnóstico alternativo. Pero una radiografía simple de tórax no puede excluir el diagnóstico de COVID-19, debido a que su sensibilidad depende del momento de la obtención de imágenes y la gravedad de la afectación pulmonar. (Puentes Suarez, Valencia Gamarra, Arteaga Rodriguez, Suárez Uribe, \& Espitia Soto, 2021)

Los hallazgos de COVID-19 más comunes incluyen la consolidación pulmonar y las opacidades en vidrio esmerilado. No obstante, con una sensibilidad aproximada del $69 \%$, las densidades de vidrio esmerilado, observadas en la tomografía, a menudo son extremadamente difíciles de correlacionar. Las opacidades pulmonares a veces pueden ser otro descubrimiento para considerar en la radiografía de tórax es la neumonía bilateral. A diferencia de la neumonía bacteriana adquirida en la comunidad, el COVID-19 produce opacidades pulmonares en 
más de un lóbulo y frecuentemente de forma bilateral. (Puentes Suarez, Valencia Gamarra, Arteaga Rodriguez, Suárez Uribe, \& Espitia Soto, 2021)
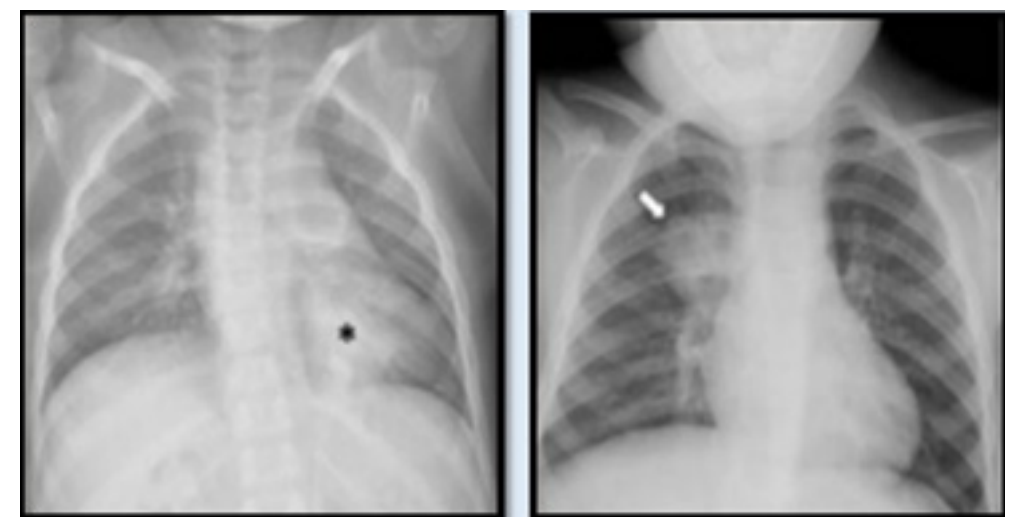

Imagen 1 y 2. Radiografías de tórax, AP, apariencia atípica con infiltrados generalizados bilaterales en paciente de 9 años COVID-19 (+); apariencia atípica que presenta condensación supralobular izquierda en paciente de 4 años COVID-19 (-).

Fuente: SERAM, Vol. 10; 2020. (Rodríguez López, Barragán Urbano, Martínez Jerez, \& Chacón Zambrano, 2020)
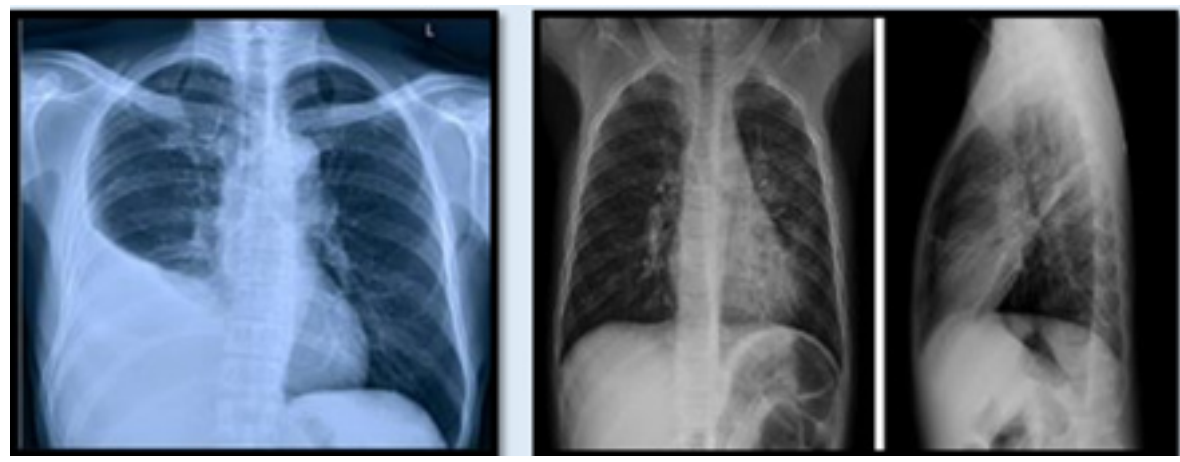

Imagen 3 y 4. Radiografías de tórax, AP y lateral, atelectasia y derrame basal izquierdo en 29 años COVID-19 (+); imágenes bilaterales medias en vidrio esmerilado en paciente de 34 años COVID-19 (+)

Fuente: SERAM, Vol. 10; 2020. (Rodríguez López, Barragán Urbano, Martínez Jerez, \& Chacón Zambrano, 2020)

Se podría encontrar como único hallazgo poco frecuente, una consolidación lobar o focal e incluso una adenopatía, derrame pleural, nódulos o masas. Teniendo en cuenta estos signos radiológicos, en el consenso sobre informe de las imágenes de COVID-19 en el que participaron el RSNA, el ACR y la Society of Thoracic Radiology, se acordó una clasificación de los hallazgos en la neumonía por COVID-19 en 4 categorías:

1. Hallazgos típicos de neumonía por COVID-19

2. Hallazgos indeterminados

3. Hallazgos atípicos

4. Negativo para neumonía

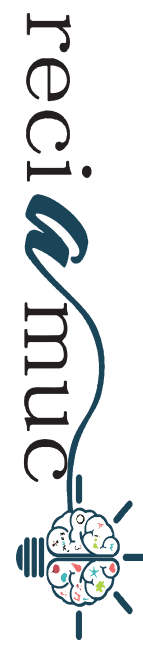


Tabla 2. Correlación entre los hallazgos radiológicos y la cuantificación de la gravedad clínica.

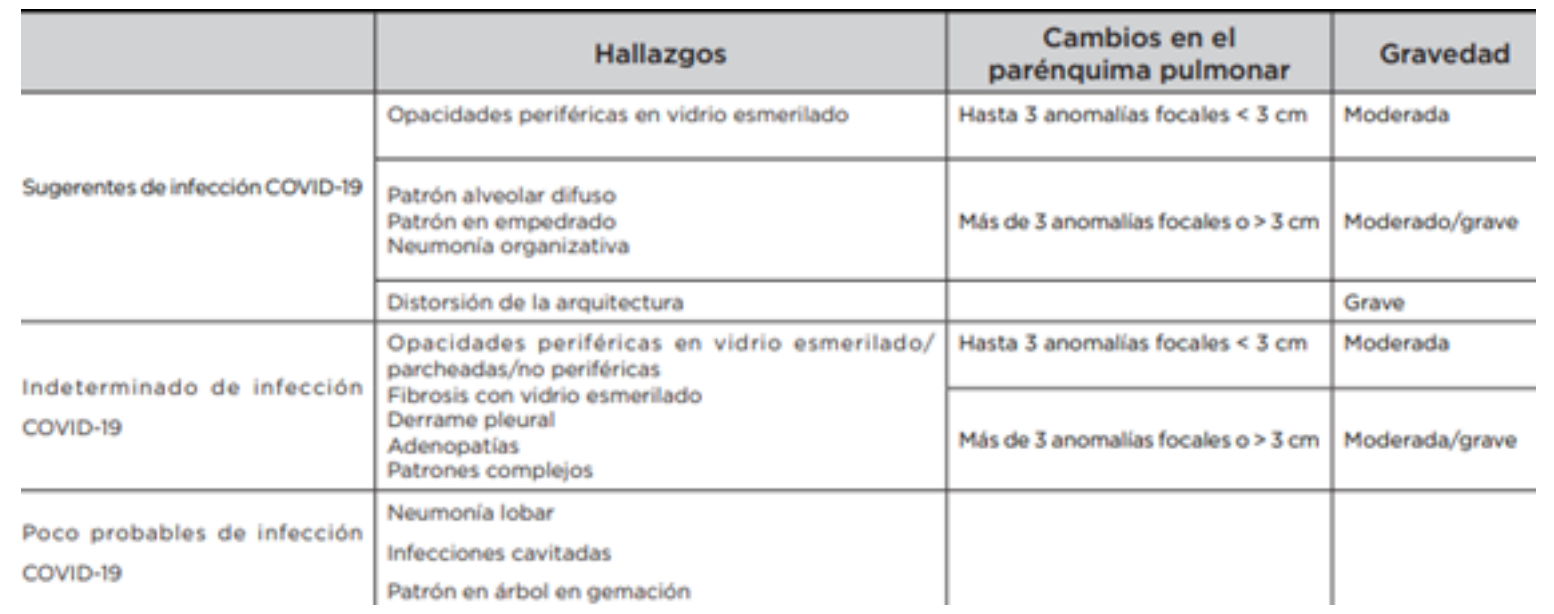

Fuente: Adaptada de The Brittish Institut of Radiology. (Richardson, Vergara, Salcedo, A., \& Cabarcas, 2020)

Tomografía axial computarizada: Se observan consolidaciones o áreas de vidrio esmerilado bilateral. También con predominio subpleural y con engrosamiento pleural asociado, esto último principalmente en adultos mayores. Los cambios en TAC pueden preceder a la positividad de la RTPCR y también puede ser predictor de severidad, principalmente cercano al día 10 de sintomatología. La necesidad de realizar una TAC implica un alto riesgo de transmisión nosocomial, por lo que se debe considerar solo si es realmente necesario y si no hay algún otro estudio que pueda sustituirlo. (Madrigal-Rojas, Quesara-Loria, García-Sanchez, \& Solano-Chinchilla, 2020)

Los hallazgos imagenológicos descritos hasta ahora como típicos son: el patrón en vidrio esmerilado, el cual suele ser el primer hallazgo tanto en radiografía simple como en TC, con incidencias de 85,49 \%; la distribución mayoritariamente periférica y subpleural (incidencia 76,95 \%) con predominio hacia los lóbulos inferiores en segmentos posteriores y con menor frecuencia dentro del lóbulo medio derecho. (Richardson, Vergara, Salcedo, A., \& Cabarcas, 2020)
A la hora de reportar oficialmente el hallazgo radiológico en la $\mathrm{TC}$, se recomienda usar las categorías de hallazgos en las imágenes descritas en el consenso del RSNA, la Society of Thoracic Radiology (STR) y el ACR que deben emplearse en el informe radiológico. (Rodríguez López, Barragán Urbano, Martínez Jerez, \& Chacón Zambrano, 2020) 
Tabla 3. Lenguaje propuesto para el informe de hallazgos tomográficos relacionados con la COVID-19

\begin{tabular}{|c|c|c|c|}
\hline $\begin{array}{l}\text { Clasificación } \\
\text { imagenológica } \\
\text { de neumonía } \\
\text { por COVID-19 }\end{array}$ & Fundamentos & Hallazgos tomográficos & $\begin{array}{l}\text { Lenguaje sugerido para el } \\
\text { informe }\end{array}$ \\
\hline Apariencia tipica & $\begin{array}{l}\text { Hallazgos } \\
\text { imagenolbgicos } \\
\text { comünmente } \\
\text { informados con } \\
\text { mayor especificidad } \\
\text { para neumonia por } \\
\text { COVID-19. }\end{array}$ & $\begin{array}{l}\text { Areas de vidrio esmerilado periferica, bilateral con o } \\
\text { sin consolidación, o septos interlobulillares (patrón en } \\
\text { empedrado). } \\
\text { Áreas de vidrio esmerilado multifocal de morfologia } \\
\text { redondeada con o sin consolidación, o septos } \\
\text { interlobulillares (patrón en empedrado). } \\
\text { Signo del halo reverso y otros hallazgos de neumonia de } \\
\text { organización (visto posteriormente en la enfermedad). }\end{array}$ & $\begin{array}{l}\text {-Se encuentran hallazgos comúnmente } \\
\text { informados en neumonia por COVD-19. Otros } \\
\text { procesos, como la influenza y neumonia de } \\
\text { organizacion, como puede ser visto en } \\
\text { toxicidad por drogas y enfermedades del } \\
\text { tejido conectivo, pueden causar un patrón } \\
\text { imagenolbgico similar". }\end{array}$ \\
\hline $\begin{array}{c}\text { Apariencia } \\
\text { indeterminada }\end{array}$ & $\begin{array}{l}\text { Hallazgos no } \\
\text { especificos de } \\
\text { neumonia por } \\
\text { COVID-19. }\end{array}$ & $\begin{array}{l}\text { Ausencia de caracteristicas tipicas y presencia de: } \\
\text { Areas de vidrio esmerilado multifocal, difuso, perihiliar } \\
\text { o unilateral con o sin consolidación, sin una distribución } \\
\text { especifica y no son redondeadas o no periféricas. Algunas } \\
\text { areas pequenas de vidrio esmerilado con una distribución } \\
\text { no periférica, no redondeadas. }\end{array}$ & $\begin{array}{l}\text {-Se encuentran hallazgos imagenológicos } \\
\text { que pueden ser vistos en neumonia por } \\
\text { COVID-19; sin embargo, no son especificos } \\
\text { y pueden ocurrir con una variedad de } \\
\text { procesos infecciosos o no infecciosos". }\end{array}$ \\
\hline Atipico & $\begin{array}{l}\text { Hallazgos poco } \\
\text { comunes o no } \\
\text { informados en } \\
\text { neumonia por } \\
\text { COVID-19. }\end{array}$ & $\begin{array}{l}\text { Ausencia de hallazgos tipicos o indeterminados y } \\
\text { presencia de: } \\
\text { Consolidación lobar aislada o segmentaria sin vidrio } \\
\text { esmerilado. } \\
\text { Nodulos pequenos (centrilobulillares, "arbol en } \\
\text { gemación"). } \\
\text { Cavitación pulmonar. } \\
\text { Engrosamiento liso de los septos interlobulillares con } \\
\text { derrame pleurat. }\end{array}$ & $\begin{array}{l}\text {-Se encuentran hallazgos imagenologicos } \\
\text { que han sido informados de manera atipica } \\
\text { en neumonia por COVID-19 (se deben } \\
\text { considerar diagnosticos alternos)". }\end{array}$ \\
\hline $\begin{array}{l}\text { Negativo para } \\
\text { neumonia }\end{array}$ & $\begin{array}{l}\text { No hay hallazgos de } \\
\text { neumonia. }\end{array}$ & No hay hallazgos tomograficos que sugieran neumonia. & $\begin{array}{l}\text { "No se encuentran hallazgos tomograficos } \\
\text { que indiquen neumonia. (Nota: La TC } \\
\text { de tórax puede ser negativa en etapas } \\
\text { tempranas de neumonia por COViD-19)". }\end{array}$ \\
\hline
\end{tabular}

Notas: 1. La inclusión en un informe de los items anotados entre partentesis en la columna de "Lenguaje sugerido para el informe", puede depender de la sospecha clinica, la prevalencia local, el estado del paciente y los procedimientos locales con respecto al informe 2 . La TC no es un sustituto de la RT-PCR considere realizar pruebas de acuerdo con las recomendaciones y procedimientos locales y la disponibilidad de RT.PCR.

Fuente: (Richardson, Vergara, Salcedo, A., \& Cabarcas, 2020)

La Evolución de los cambios en la TC de tórax, se hace con base en 4 etapas y son:

- Etapa inicial / inicial (0-4 días): con TC normal o sólo GGO y hasta la mitad de los pacientes tienen TC de tórax normales dentro de los dos días posteriores al inicio de los síntomas, por lo cual no es confiable en su totalidad.

- Etapa progresiva (5-8 días): mayor GGO y patrón de empedrado.

- Etapa pico (9-13 días): consolidación

- Etapa de absorción (> 14 días): con una mejoría en el curso de la enfermedad, aparecen «líneas fibrosas» y las anomalías se resuelven al cabo de un mes o más.

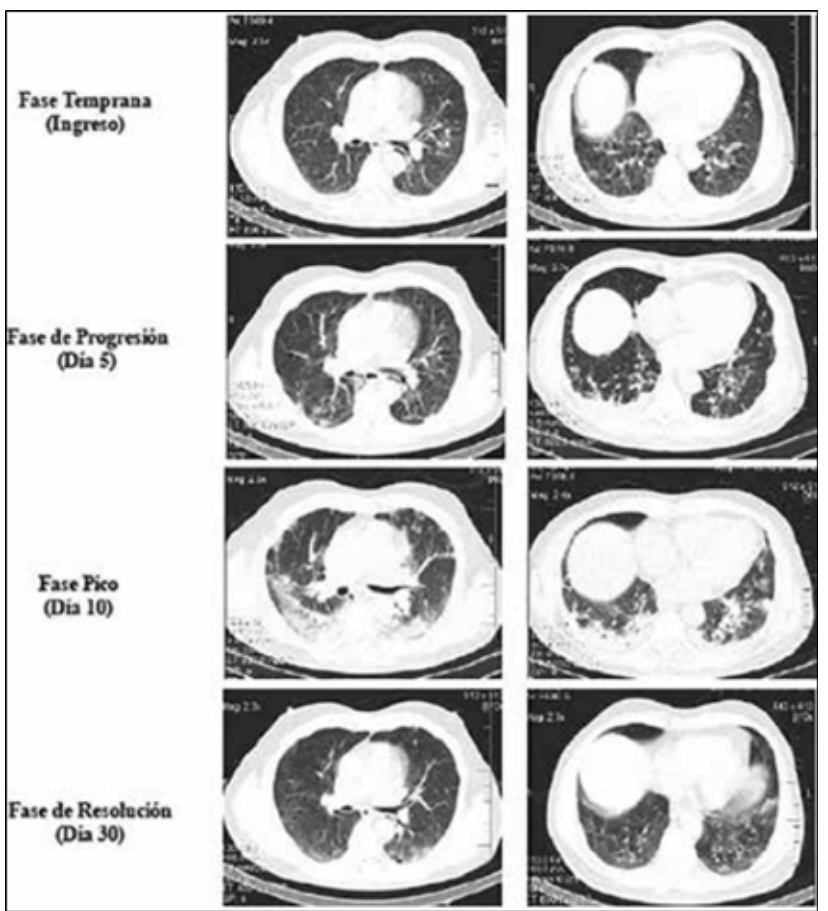

Imagen 5. Hallazgos en la TC de tórax según el estadio de la COVID-19

Fuente: (Zarrelli, y otros, 2021)

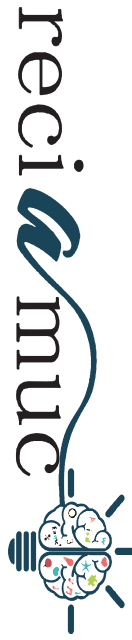


I En un paciente con infección confirmada de COVID-19 con síntomas respiratorios, deben considerarse el diagnóstico de Síndrome de Respuesta Inmune Trombótica (RITAC) cuándo presenta uno o más de los siguientes criterios diagnósticos:

- Dímero D: > $1.000 \mathrm{ng} / \mathrm{mL}$,

- Ferritina $>500 \mathrm{ng} / \mathrm{mL}$,

- Disnea de rápida progresión,

- Hipoxemia refractaria,

- Fenómenos trombóticos y

- Shock.

Los pacientes presentan datos clínicos y de laboratorio compatibles con el Síndrome de Activación Macrofágica (SAM), indicando que la etiología es una respuesta inmune exagerada. El parámetro de laboratorio más apropiado para reconocerlo es el Dímero-D elevado y como consecuencia, se producen múltiples episodios trombóticos, des- de isquemia periférica y tromboembolismo pulmonar hasta Coagulación Intravascular Diseminada (CID). El diagnóstico precoz es imprescindible para disminuir la mortalidad de estos pacientes y es allí donde el papel de las imágenes diagnosticas se torna vital. (Rodríguez López, Barragán Urbano, Martínez Jerez, \& Chacón Zambrano, 2020)

Recientemente se ha publicado un estudio comparativo entre la neumonía por COVID-19 y otras neumonías víricas. Las características más discriminatorias para la neumonía por COVID-19 incluyeron:

- Distribución periférica (80\% vs. $57 \%$, p $<0.001)$

- Opacidad de vidrio deslustrado $(91 \%$ vs. $68 \%,<0.001$

- Engrosamiento vascular (58\% frente a 22\%, p $<0.001$ (Rodríguez López, Barragán Urbano, Martínez Jerez, \& Chacón Zambrano, 2020)

Tabla 4. Clasificación de los hallazgos Tomográficos de la Neumonía por la COVID-19 según la Sociedad de Radiología de Norteamérica (RSNA).

\begin{tabular}{|c|c|c|}
\hline Patrón & Hallazgo & Interpretación \\
\hline Tipico & $\begin{array}{l}\text { OVD de distribución bilateral y periférica, con o sin } \\
\text { focos de consolidación o líneas intralobulares visibles } \\
\text { (Patrón de empedrado o "Crazy paving) } \\
\text { OVD multifocales de morfologia redondeada con o sin } \\
\text { consolidación o lineas intralobulares visibles (Patrón } \\
\text { de empedrado o "Crazy paving"). } \\
\text { Signo del halo reverso u otro hallazgo de neumonia } \\
\text { organizada }\end{array}$ & $\begin{array}{l}\text { Hallazgos imagenolठgicos de } \\
\text { gran especificidad para la } \\
\text { COVID-19. }\end{array}$ \\
\hline Indeterminado & $\begin{array}{l}\text { Ausencia de hallazgos típicos y presencia de: } \\
\text { OVP multifocal, difusa, perihiliar o unilateral, con o } \\
\text { sin consolidación, sin una distribución especifica, no } \\
\text { redondeada no periférica. } \\
\text { Pocas y pequenas OVD sin una distribución periférica } \\
\text { ni morfologia redondeada. }\end{array}$ & $\begin{array}{l}\text { Hallazgos imagenologicos no } \\
\text { especificos para la COVID-19 }\end{array}$ \\
\hline Atipico & $\begin{array}{l}\text { Ausencia de hallazgos típicos o indeterminados, con } \\
\text { presencia de lo siguiente: } \\
\text { Consolidación aislada lobar o segmentaria sin } \\
\text { presencia de OVD; nodulos pequenos discretos } \\
\text { (Centrolobulillares con morfologia de árbol en brote); } \\
\text { cavitación pulmonar; engrosamiento septal } \\
\text { interlobulillar con derrame pleural }\end{array}$ & $\begin{array}{l}\text { Hallazgos no comunes de la } \\
\text { COVID-19 }\end{array}$ \\
\hline Negativo & $\begin{array}{l}\text { No hallazgos tomográficos que sugieran presencia de } \\
\text { neumonia }\end{array}$ & No hallazgos de neumonia. \\
\hline
\end{tabular}

Fuente: Sociedad de la Radiología de Norteamérica (RSNA), 2020. (Zarrelli, y otros, 2021) 
Tabla 5. Clasificación de los hallazgos Tomográficos de la Neumonía por la COVID-19 según la Sociedad Bariátrica de imágenes (BSTI).

\begin{tabular}{|c|c|}
\hline Patrón & Descripciôn \\
\hline $\begin{array}{l}\text { Clasico } \\
\text { (100\% confianza para la COVID-19) }\end{array}$ & $\begin{array}{l}\text { A predominio del lobulo inferior, periférico, múltiple, bilateral, } \\
\text { foco de OVD con o sin patrón en empedrado, consolidación } \\
\text { periférica, halo reverso/patrón perilobulillar, broncograma aéreo }\end{array}$ \\
\hline $\begin{array}{l}\text { Probable } \\
\text { (71-99 \% confianza para la COVID-19) }\end{array}$ & $\begin{array}{l}\text { Mezcla de consolidación bronco céntrica y periférica en el Iobulo } \\
\text { inferior. Halo reverso/patrón perilobulillar. Escasos OVD }\end{array}$ \\
\hline $\begin{array}{l}\text { Indeterminado } \\
(<70 \% \text { confianza para la COVID-19) }\end{array}$ & $\begin{array}{l}\text { No entra dentro de la definición, probable y no probable. } \\
\text { Manifiesta los criterios anteriores, pero el contexto clínico está } \\
\text { mal, o sugiere un diagnostico alternativo (Ejemplo, enfermedad } \\
\text { intersticial pulmonar en el contexto de una enfermedad del tejido } \\
\text { conectivo). }\end{array}$ \\
\hline $\begin{array}{c}\text { No COVID-19 } \\
(70 \% \text { confianza para COVID }-19)\end{array}$ & $\begin{array}{l}\text { Neumonia Lobar. Infecciones cavitadas. Patrón de árbol en } \\
\text { brote/nodulo centrolobulillares. Linfadenopatias. Derrame pleural. } \\
\text { Fibrosis pulmonar establecida. }\end{array}$ \\
\hline
\end{tabular}

Fuente: Sociedad Británica de imágenes torácicas, 2020.

La severidad de la enfermedad se puede determinar de acuerdo al porcentaje de afectación pulmonar, considerando leve < $25 \%$, moderado de $25 \%-75 \%$ y severo $>75 \%$. Con la estadificación de severidad en dicha escala, los pacientes categorizados como leve- moderado tendrán una baja probabilidad de muerte y los pacientes severos una alta probabilidad de muerte. En la actualidad la tomografía de tórax en una herramienta con alta sensibilidad para de- tectar la presencia de afectación pulmonar por la COVID-19, de marcada utilidad para determinar el estadio de la enfermedad, la progresión o mejoría de la misma y diagnosticar la presencia de complicaciones. El uso de un léxico adecuado y de las clasificaciones diagnósticas y de severidad, permitirán un reporte uniforme de los hallazgos imagenológicos, lo cual es fundamental para la toma de decisiones clínicas y terapéuticas. (Zarrelli, y otros, 2021)

Tabla 6. Clasificación del grupo de trabajo de la COVID-19 de la Sociedad de Radiología Holandesa (CO-RADS)

\begin{tabular}{|c|c|c|}
\hline CORADS & $\begin{array}{l}\text { Nivel de Sospecha } \\
\text { para COVID-19 }\end{array}$ & Hallazgos Tomográficos \\
\hline 0 & No interpretable & Escaneo técnicamente insuficiente para asignar una puntuacion \\
\hline 1 & Muy baja o improbable & Normal o no infeccioso \\
\hline 2 & Baja probabilidad & $\begin{array}{l}\text { Anormalidades compatibles con infecciones no } \\
\text { relacionadas con la COVID-19. No hay datos tipicos de la } \\
\text { COVID-19. }\end{array}$ \\
\hline 3 & Intermedia & $\begin{array}{l}\text { Hay anormalidades que indican infección, pero no esta } \\
\text { clara su relación con la COVID-19. }\end{array}$ \\
\hline 4 & Alta probabilidad & $\begin{array}{l}\text { Anormalidades que hacen sospechar de la COVID-19: } \\
\text { OVD unilateral, consolidaciones multifocales sin ningún } \\
\text { otro hallazgo típico. Cuadro clínico sospechoso de la } \\
\text { COVID-19. }\end{array}$ \\
\hline 5 & Muy alta probabilidad & $\begin{array}{l}\text { Tipica para la COVID-19: imágenes de OVD multifocales, } \\
\text { distribución basal y periférica, adelgazamiento vascular, } \\
\text { patrón en empedrado. }\end{array}$ \\
\hline 6 & Confirmada & $\begin{array}{l}\text { Hallazgos tipicos de la COVID-19 y RT-PCR positivo } \\
\text { para SARS-CoV-2. }\end{array}$ \\
\hline
\end{tabular}

Fuente: Sociedad Británica de imágenes torácicas, 2020. 
La TC de tórax proporciona una delimitación con una alta sensibilidad de hasta el 98 \% en neumonía por COVID-19. Empero, el uso de la TC como prueba de diagnóstico para el virus se ha cuestionado, pues no otorga ningún beneficio clínico adicional, pero podría dar lugar a una falsa sensación de seguridad, en vista de que el $20 \%$ de los pacientes sintomáticos tienen resultados negativos en la TC. El resultado de una TC de tórax no altera el manejo del paciente, múltiples sociedades recomiendan no utilizarla para el cribado y el diagnóstico de la enfermedad. (Puentes Suarez, Valencia Gamarra, Arteaga Rodriguez, Suárez Uribe, \& Espitia Soto, 2021)

Cada vez que avanza la enfermedad, las opacidades en vidrio esmerilado pueden aumentar en tamaño y en grado de afectación, en este sentido, se pueden observar patrones de pavimentación o consolidaciones adicionales. La presencia de consolidaciones con broncograma aéreo, afectación pulmonar central y derrame pleural en la TC de tórax inicial se presenta, con mayor frecuencia, en pacientes graves que necesitan cuidados intensivos. (Puentes Suarez, Valencia Gamarra, Arteaga Rodriguez, Suárez Uribe, \& Espitia Soto, 2021)

Ultrasonido. Ha mostrado una sensibilidad similar a la de TAC, para detectar engrosamiento pleural, consolidaciones subpleurales y vidrio esmerilado. Esto con los beneficios de disminuir la exposición del personal hospitalario, la posibilidad de realizarlo al pie del paciente y su potencial para dar seguimiento diario. Esta descrito que con esta metodología los hallazgos presentan mayor severidad cercano al décimo día de inicio de síntomas. (Madrigal-Rojas, Quesara-Loria, García-Sanchez, \& Solano-Chinchilla, 2020)

La Sociedad Fleischner plantea tres escenarios según la clínica y la disponibilidad de recursos. Se destaca la recomendación de realizar imágenes radiológicas en los pacientes con manifestaciones clínicas mo- deradas-graves, independientemente del resultado de la prueba de la COVID-19, ya que establecen el estado pulmonar basal y ayudan a identificar anormalidades cardiopulmonares subyacentes o incluso causadas por la misma infección, y que pueden facilitar la estratificación del riesgo, además de que deben hacerse en el paciente que cursa con empeoramiento clínico. (Richardson, Vergara, Salcedo, A., \& Cabarcas, 2020)

\section{COVID-19 y tecnologías actuales}

La Inteligencia Artificial se ha vuelto una disciplina que trata cualquier ámbito, en el trabajo Amou Ghanem (2021). se ha realizado una aplicación en el ámbito de la salud. Se ha creado un modelo de aprendizaje automático, que clasifica imágenes de rayos- $X$ del tórax, en positivas o negativas frente al virus COVID-19, previamente clasificados.

En los últimos años, la inteligencia artificial y el aprendizaje profundo (DL, acrónimo del inglés, deep learning), se han convertido en tecnologías de gran interés en el campo de la medicina. El DL forma parte del aprendizaje automático basado en algoritmos con estructura de red neuronal multicapa, inspirado en el cerebro humano. Aunque no es un concepto nuevo, el rápido crecimiento de la informática y la disponibilidad de conjuntos de datos etiquetados de imágenes torácicas han facilitado su éxito y podrían alterar significativamente la forma en que se practica la medicina. Estos algoritmos son capaces de aprender de sus errores y de reorganizar sus redes neuronales, con lo que, igual que los seres humanos, están sometidos a un constante aprendizaje. (Corbacho Abelaira, Ruano-Ravina, \& Fernández-Villar, 2021)

La radiografía de tórax y la tomografía computarizada, 2 pilares de la radiología torácica, han sido de las modalidades de imagen más investigadas y han ido superando limitaciones de otras técnicas más convencionales al proporcionar interpretabilidad, transparencia, reproducibilidad y un alto 
rendimiento para alcanzar la credibilidad de los radiólogos, que las implementan en su práctica clínica. (Corbacho Abelaira, Ruano-Ravina, \& Fernández-Villar, 2021)

La Figura 6 es una adaptación del algoritmo creado por Vaisha y colaboradores, explica cómo algunos estudios sugieren que la par- ticipación de la IA, en los pasos importantes del tratamiento de alta precisión, reduce la complejidad y el tiempo necesario. Así, el médico no solo se centra en el tratamiento del paciente, sino en el control de la enfermedad con la aplicación de IA. (Puentes Suarez, Valencia Gamarra, Arteaga Rodriguez, Suárez Uribe, \& Espitia Soto, 2021)
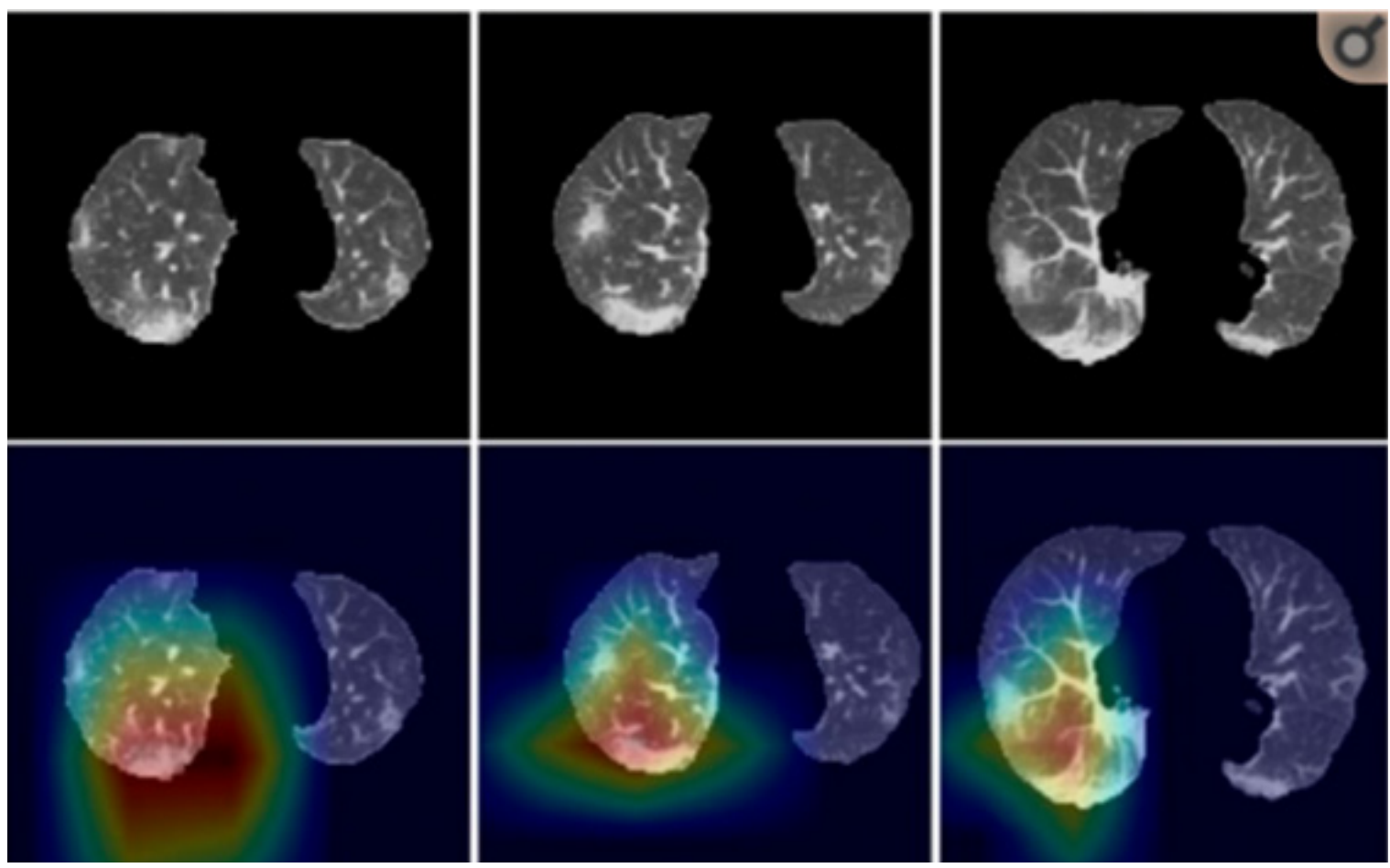

Imagen 5. Representativos de los mapas de calor generados con el método GRADCAM.

Fuente: Tomada para fines académicos de: artificial inteligence distinguishes COVID-19 from commnity acquired pneumonia on Chest CT. (Puentes Suarez, Valencia Gamarra, Arteaga Rodriguez, Suárez Uribe, \& Espitia Soto, 2021)

Este es un sistema de IA que usa una capa convolucional final para producir un mapa de localización aproximado que resalta lo importante en la imagen y predice el concepto, en este caso, la neumonía. El color rojo resalta la región de activación asociada con la clase predicha. la imagen superior muestra la neumonía por COVID-19 y la imagen inferior la adquirida en la comunidad. (Puentes Suarez, Valencia Gamarra, Arteaga Rodriguez, Suárez Uribe, \& Espitia Soto, 2021)
Se ha conseguido desarrollar diferentes modelos de redes neuronales convolucionales con una precisión mayor al $70 \%$ en la detección de COVID-19. El modelo que ofrece un mejor rendimiento es que utiliza la red pre-entrenada VGG-16 junto con aumento de datos, llegando a una precisión del $87 \%$. Dicho modelo se ha utilizado para la creación de una aplicación web capaz de clasificar las imágenes en cuatro categorías: normal, opacidad torácica, neumonía viral y neumonía COVID-19. Es importante realizar modelos de aprendizaje automáti- 
cos en entornos con mayor capacidad computacional como mediante la utilización de GNU/Linux o la utilización de la plataforma Google Calab que permite acceso gratuito a servidores GPUs. (Alfonso López, 2021)

La inteligencia artificial ha contribuido a mejorar el diagnóstico de la COVID-19, en la que ha conseguido excelentes precisiones, incluso en validaciones externas, lo que hace pensar en la posibilidad de su generalización. Como se ha descrito, cuando los humanos y la inteligencia artificial trabajan juntos, el rendimiento diagnóstico mejora, aunque esto no significa necesariamente mejores resultados para el paciente. (Corbacho Abelaira, Ruano-Ravina, \& Fernández-Villar, 2021)

El uso de técnicas de Inteligencia Artificial (IA) pudiera mitigar el efecto de no contar con un especialista en rayos $X$ para evaluar las imágenes a tiempo completo haciendo evaluaciones. Además, puede dotar a los doctores de una herramienta de alerta temprana basada en las imágenes de rayos $X$ en el camino de la detección del COVID-19, así como de otras patologías como neumonías virales y bacterianas de disímiles causas. Existe en la literatura científica un gran número de trabajos que abordan el tema de la clasificación automática de COVID-19 a partir de imágenes TC y RX utilizando IA. La mayoría de ellos alentadores, pues reportan elevados índices de desempeño, incluso superiores a los humanos. Sin embargo, estos resultados no convencen a los radiólogos. Por esta razón, las expectativas que se han creado con estos estudios deben manejarse con cuidado por la comunidad científica que trabaja en IA, es necesario demostrar científicamente su pertinencia y poder de generalización (Kermany, et al.,2018; Baltruschat, et al., 2019 y Laghi, A. 2020 en López Cabrera, Portal Díaz, Orozco Morales, \& Pérez Díaz, 2020)

Existe a nivel internacional un limitado conjunto de imágenes RX positivas a COVID-19 de forma libre en Internet para el uso de la comunidad científica. La mayoría de los estudios completan las datas con imágenes negativas a partir de otras fuentes de datos. Las imágenes poseen marcadas diferencias entre los distintos conjuntos. Esto propicia muy buenos resultados en la clasificación automática de COVID-19, al evaluar usando un subconjunto de imágenes del conjunto usado. No obstante, varios estudios reportan poco o ningún poder de generalización, al evaluar los modelos entrenados en conjuntos propios. Incluso, los modelos que fueron entrenados usando técnicas de pre-procesamiento, que trataban de eliminar los sesgos pertenecientes a los conjuntos de datos, mostraron pobres resultados. Por tanto, la mayoría de los resultados alcanzados hasta el momento, que se reportan en la literatura científica, presentan modelos que aprenden características propias de los conjuntos donde fueron entrenados. La ausencia de un protocolo de evaluación adecuado, hace que la mayoría de los modelos desarrollados hasta el presente, tengan aún escaso valor en ambientes clínicos. (López Cabrera, Portal Díaz, Orozco Morales, \& Pérez Díaz, 2020)

\section{Buenas prácticas en la obtención y ma- nejo de las muestras para el diagnóstico de la COVID-19}

La bioseguridad es un aspecto muy importante que se debe considerar durante la toma y el manejo de la muestra requerida para el diagnóstico de la enfermedad COVID-19. La OMS recomienda el nivel 2 para realizar las pruebas de diagnóstico. El personal de laboratorio debe tener entrenamiento específico en el manejo de agentes patógenos, bajo la supervisión directa de un investigador competente, según las normas de bioseguridad de cada laboratorio. (Aguilar Ramírez, y otros, 2020)

Se ha considerado que las muestras del tracto respiratorio superior aumentan la sensibilidad de las pruebas moleculares, además de ser más fáciles de obtener. Para la toma de muestra, la OMS recomienda que 
el material se colecte con un hisopo de punta sintética (por ejemplo, nailon o dacrón) y un eje de aluminio o plástico. (Aguilar Ramírez, y otros, 2020)

El procedimiento recomendado para recoger una muestra nasofaríngea de calidad implica insertar el hisopo y frotar en la fosa nasal paralela al paladar, manteniendo el hisopo en su lugar durante unos segundos para permitir la secreción y la absorción. Inmediatamente después se coloca el hisopo en un tubo estéril que contiene $2-3 \mathrm{ml}$ de medio de transporte viral. El procedimiento para recolectar muestras de la orofaringe (por ejemplo, garganta) implica frotar la faringe posterior, evitando la lengua e, inmediatamente, colocar el hisopo en otro tubo estéril separado que también contiene 2-3 $\mathrm{ml}$ de medios de transporte virales. Está demostrado que el uso incorrecto de los hisopos, la absorción inapropiada de material de diagnóstico y la inserción en viales inadecuados pueden causar errores de diagnóstico. (Aguilar Ramírez, y otros, 2020)

Los errores preanalíticos en los estudios pueden ocurrir por falta de identificación o identificación errónea de la muestra, la colección inadecuada o la cantidad insuficiente de la muestra por analizar, las condiciones imprecisas de transporte y almacenamiento de la muestra (exposición a lesiones, cadena de frío poco confiable, tiempo de transporte prolongado) y la presencia de sustancias interferentes (por ejemplo, liberación de componentes celulares que pueden interferir en el ensayo debido a la congelación de sangre entera, uso de aditivos inapropiados). La viabilidad de la muestra es responsabilidad del personal que la recoge y que debe asegurar la cadena de custodia hasta que dicha muestra llega al laboratorio. (Aguilar Ramírez, y otros, 2020)

Cuando el laboratorio que realiza el diagnóstico no es el responsable del proceso de toma de la muestra, deberá solicitar toda la información importante para el manejo, embalaje y condiciones de transporte de la muestra. Además, se debe contar con todos los datos relevantes que permitan la correcta identificación de la muestra (nombre y apellidos del usuario o código, fecha de nacimiento, tipo de muestra que se envía y fecha de recolección). Estos y otros detalles respecto al manejo de las muestras de pacientes se han protocolizado debido a su importancia en la condición pandémica actual. (Aguilar Ramírez, y otros, 2020)

\section{Conclusiones}

El rol de las imágenes diagnósticas se hace cada día más relevante en medio de la pandemia, pues queda demostrada su importancia como diagnóstico, protocolo de tratamiento y seguimiento en el paciente positivo con COVID-19. Resulta una, ayuda diagnóstica efectiva frente a dudas o cuadros clínicos atípicos de pacientes con e infección por SARS-Cov-2.

La radiografía de tórax es la imagen ideal para sospecha de COVID-19 en etapa inicial, aun cuando la PCR resulte negativa pero hayan síntomas que correspondan con la enfermedad. Resulta ideal por su capacidad de traslado y movilización, además que suelen ser de mayor accesibilidad por su bajo costo respecto a la Tomografía computarizada (TC) sin embargo, esta ultima resulta necesaria y definitiva para la confirmación de casos sospechosos con afecciones pulmonares por contagio con el virus SARS-COV-2.

Aun cuando el ultrasonido también es utilizado, la bibliografía consultada dada la delimitación de búsqueda no reporta una utilidad común para el diagnostico de COVID-19, aunque puede ser de utilidad sobretodo en la etapa inicial de la enfermedad.

Las características de las imágenes pueden verse en neumonía por COVID-19 aunque no son específicas y pueden concurrir en una variedad de procesos infecciosos y no infecciosos, por tanto, se deberán considerar diagnósticos alternativos. (Rodríguez López, Barragán Urbano, Martínez Jerez, \&

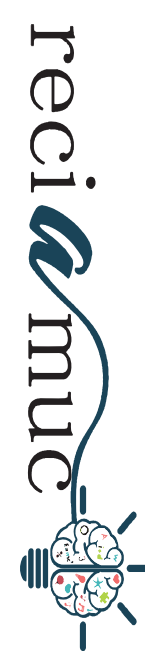


Chacón Zambrano, 2020)

Es por ello que se han publicado consensos médicos para el análisis y conclusiones de los estudios de imágenes, evitando confusiones en el diagnóstico que pongan en riesgo la propagación del virus y sobre todo la vida de los pacientes por un diagnóstico inadecuado que derive en consecuencias graves ocasionadas por el virus.

Las distintas variantes que se han conocido del SARS-COV-2 mantiene en alerta a todo profesional médico y técnico en el área de la salud y la medicina, pues se siguen descubriendo características distintas de manifestaciones clínicas en pacientes con COVID-19, lo que permite inferir que lo que ya se conoce es apenas un inicio, y que se deben seguir desarrollando tecnologías que agrupen los conocimientos desarrollados y propicien los nuevos.

El apoyo en la biotecnología es una oportunidad para enfrentar esta pandemia, definitivamente la capacidad de la IA en el almacenaje de información, la relación de patrones y la velocidad de diagnóstico es una oportunidad única que ofrece la evolución científica frente a los eventos pandémicos vivimos por la humanidad. Es crucial el papel que desempeñan los elementos humanos en la parametrización, prueba y aprobación de tecnologías útiles que mejore el alcance la atención médica para ganar la batalla en contra del SARS-COV-2 y la COVID-19.

\section{Bibliografía}

Aguilar Ramírez, P., Enriquez Valencia, Y., Quiroz Carrillo, C., Valencia Ayala, E., de León Delgado, J., \& Pareja Cruz, A. (2020). Pruebas diagnósticas para la COVID-19: la importancia del antes y el después. Horizonte Médico, 20(2), e1231.

Alfonso López, B. (2021). Deteccion precóz de covid-19 a partir de imágenes de radiografías de tórax mediante redes neuronales convolucionales. Catalunya: Universitat Oberta de Catalunya.
Amou Ghanem, F. Z. (2021). Detección de efectos del virus Covid19 en imágenes de rayos $X$ mediante redes neuronales.

Corbacho Abelaira, M. D., Ruano-Ravina, A., \& Fernández-Villar, A. (2021). Inteligencia artificial en radiología torácica. ¿Un reto en tiempos de la COVID-19? Arch Bronconeumol, 57, 15-16.

López Cabrera, J., Portal Díaz, J. A., Orozco Morales, R., \& Pérez Díaz, M. (octubre-diciembre de 2020). Revisión crítica sobre la identificación de covid-19 a partir de imágenes de rayos $x$ de tórax usando técnicas de inteligencia Artificial. Revista Cubana de Transformación Digital, 1(3), 67-99.

Madrigal-Rojas, J., Quesara-Loria, M., García-Sanchez, M., \& Solano-Chinchilla, A. (enero-junio de 2020). SARS CoV-2, manifestaciones clínicas y consideraciones en el abordaje diagnóstico de COVID-19. Revista Médica de Costa Rica, 85(629).

Mendoza-Ticona, A., Valencia Mesias, G., Quintana Aquehua, A., Cerpa Chacaliaza, B., García Loli, G., Álvarez Cruz, C., \& Rivero Vallenas, J. P. (2020). Clasificación clínica y tratamiento temprano de la COVID-19. Reporte de casos del Hospital de Emergencias Villa El Salvador, Lima-Perú. Acta Médica Peruana, 37(2), 186-191.

Pérez Ortiz, M. (2021). ficación de imágenes mediante algoritmos de Deep Learning: Mascarillas de COVID-19. Ingeniería de las Tecnologías de Telecomunicación, Dpto. Teoría de la Señal y Comunicaciones. Sevilla: Universidad de Sevilla.

Puentes Suarez, G., Valencia Gamarra, H. S., Arteaga Rodriguez, C. G., Suárez Uribe, Y. L., \& Espitia Soto, H. J. (2021). A propósito del COVID19, una revisión sistemática respecto al paradigma de la radiología y la inteligencia artificial. Scienti ic \& Education Medical Journal, 2(1), 142-151.

Richardson, J., Vergara, S., Salcedo, J., A., R., \& Cabarcas, C. (2020). Hallazgos imagenológicos y correlación con la escala de gravedad de la COVID-19. Revista Colombiana de Radiología, 31(1), 5269-76.

Rodríguez López, L. M., Barragán Urbano, D., Martínez Jerez, E. G., \& Chacón Zambrano, L. A. (julio- diciembre de 2020). El verdadero papel de las imágenes diagnósticas en época de pandemia por COVID-19. Revista Neuronum, 6(4), 408-427.

Slipczuk, L., Arrioja, A., Medina, H., Piamo, L., Obregón, R., Lowenstein, D., \& García, M. (2021). Recomendaciones para imágenes durante pandemia de COVID-19. Sociedad de Imágenes Cardiovasculares de la Sociedad Interamericana de Cardiología (SISIAC). 
Zarrelli, R., Hernández, M., Martínez, A., Pérez, M., Andonaegui, L., Meléndez, A., Guzmán, O. (2021). Utilidad de la tomografía de tórax en el diagnóstico de la COVID-19. Revista Venezolana de Infectología, 32(1), 5169.

\section{CITAR ESTE ARTICULO:}

Guerra Fernández, J. A., Villao Navas, C. A., \& Santos Benavides, S. A. (2021). Diagnóstico y clasificación de COVID-19 basado en imágenes. RECIAMUC, 5(4), 181-195. https://doi.org/10.26820/reciamuc/5.(4).noviembre.2021.181-195

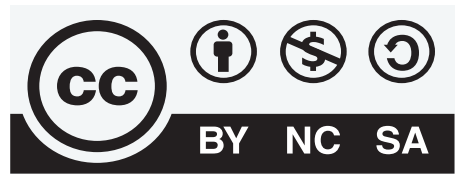

CREATIVE COMMONS RECONOCIMIENTO-NOCOMERCIAL-COMPARTIRIGUAL 4.0. 